\title{
INVESTIGATIONS ON THE CONTROL OF HOOKWORM DISEASE. VIII.
}

\author{
Experiments on the Migration of Hookworm Larvae in Solls.*
} By DONALD L. AUGUSTINE, B.S.

(Received for publication December 13, 1921.)

Historical account.

Until Baermann (1917) devised an apparatus with which hookworm larvae could be successfully isolated from the soil, little or nothing was known of their activities under natural conditions. Throughout the literature, one is impressed with the idea that the infective hookworm larvae may actively migrate for considerable distances, and may thus give rise to infestation far from the place where the eggs were originally deposited.

Claude A. Smith $(1903$, p. 710$)$ recorded that the larvae dart through a sandy soil at a lively rate for a few minutes to half an hour or more, and then straighten out and lie perfectly still for a corresponding length of time. In the report of the Porto Rico Anemia Commission $(1904$, p. 121) the statement was made that rain causes a distribution of larvae, and that this, together with their natural motility, may spread nests of soil infestation over a considerable area. Nicoll $(1917$, p. 163 ) in his discussion of the hookworm larvae, under natural conditions, made the following statement:

"The larvae now measure about $0.6 \mathrm{~mm}$. in length and are very actively motile. Unless they have been washed away previously from the faeces, they now proceed to migrate to a more suitable locality, namely: the nearest water pool or patch of moist ground. Provided even a trace of moisture be present, they are capable of traversing considerable distances and may thus give rise to infection far from the place, where the faeces were originally deposited. How far and how rapidly they may wander in this fashion is not definitely known,

* This paper is the eighth of the series on the hookworm investigations of the Department of Medical Zoology, School of Hygiene and Public Health, Johns Hopkins University, carried on with the eooperation of the International Health Board, Fockefeller Foundation. 
but judging from laboratory experiences their rate is probably not less than five feet per hour, so that in the course of 24 hours, they may have wandered 40 yards. This means that an area of 5,000 square yards might become infected within 24 hours after the larvae started to migrate, i.e., within a week after the faeces were deposited."

Chandler $(1918$, p. 259) pointed out that continual traveling in a straight line would probably never occur, but that a single stool containing hookworm eggs could easily infest at least several square yards. Similar statements on the spread of hookworm larvae were also made by Ozzard (1909, p. 779).

The first intimation that the infective hookworm larvae might be limited in their distribution throughout the soil was made by Price $(1910$, p. 205). He stated that in his opinion sub-soil pollution was not an important factor in hookworm disease, because it appears inconceivable that hookworm larvae will pass for any considerable distance through a sand and gravel sub-soil.

Based on the work of these authors, the opinion has become current that the infective hookworm larvae move out from centers of infestation and spread themselves over wide areas. This conception is founded largely upon the study of the behavior of the encapsuled larvae when mounted in water, or water and soil, on glass slides or in watch glasses, and examined microseopically. To what extent the migrations of the larvae occur from definite infested centers in soils of various types and under varying conditions, has not yet been demonstrated. The experiments which will be deseribed in this paper were carried out in Trinidad, British West Indies, from May to September, 1921, in order to gain information on this very subject.

I wish here to express my appreciation to Dr. W. W. Cort, under whose direction the investigations embodied in this and the two following papers were carried on, for his eonstant interest and helpful suggestions. Thanks are also due Dr. James E. Ackert, of the Kausas State Agricultural College, Dr. Florenee King Payne and Dr. George C. Payne, Trinidad, for assistance in securing material and for suggestions during the course of the work.

\section{MATERIAL AND METHODS.}

The larvae used in these experiments were obtained from cultures 5 to 8 days old. A detailed account of the method used in the preparation of the cultures is given in number two of this series (Cort, 
et al., 1922, p. 6). The larvae were carefully counted under the microseope, the $16 \mathrm{~mm}$. objective being used, when the hookworm larvae were mixed with other nematodes, and a lower power, when they were in pure culture. As Ancylostoma duodenale is very rare in Trinidad it may be assumed that the larvae obtained were those of Necator americanus.

Two sizes of pans were used in the experiments on migration, viz.: (1) round tin dripping pans, 13 inches in diameter and 4 inches high, and (2) pudding pans 6 inches in diameter and 2 inches high.

The soils in which these larvae were studied were selected from the district in which these experiments were carried on, the Naparima District, which is in the south central part of Trinidad. They were chosen from areas free from soil pollution, and tested in the laboratory with the isolating apparatus for the presence of hookworm larvae, and free-living nematodes. None of the samples were found to contain hookworm larvae, and where free-living nematodes were numerous, the soil was heated to $150^{\circ} \mathrm{F}$. This temperature was found to be sufficient to kill all living organisms present without altering the composition of the soil itself.

The migrations of the hookworm larvae were studied in five distinet types of soils. Type 1 was a black, rather heavy, clay. loam which contained no small stones. Type 2 was identical with type 1 , except that it contained a greater amount of humus and was lighter. These two soils are classified by Williams (1921, pp. 106-109) under the Maparina Marls or the Blaek Soils of the Maparimas. Type 3 was also a heavy elay loam distinguished by its red color. It differed from types 1 and 2, chiefly in its chemical rather than mechanical composition being deficient in lime and having a high pereentage of iron. Type 4 was a fine sand and clay mixture, light when dry or slightly moist, but heavy and compact when wet. Type 5 was a loose reddish sand, containing only a small amount of clay.

\section{EXPERIMENTS ON ACTIVE MIGRATION.}

Table 1 gives the data from a series of twenty experiments to test the active migration of infective hookworm larvae under a variety of conditions. In all the experiments, summarized in this table, the soils were placed to the depth of $1 \mathrm{~cm}$. in the 13-inch dripping pans. The center was then determined, marked by a cord circle 1 inch in diameter, and the larvae placed within this cirele. This area was 
termed Zone 1, or the center of infestation. When I wished to close an experiment the soil was further divided into Zones 2,3 and 4 . This was accomplished with an apparatus similar to a doughnut or cooky cutter. It consisted of three stationary tin bands of sufficient circumference to make each of these zones two inches wide. The soils of the three outer zones were transferred separately to units of the large isolation apparatus, without withdrawing the "cutter." The danger of mixing the soil of one zone with the next was thereby reduced to a minimum. Two units of the isolation apparatus were used for Zone 4, to keep the amount of soil in each unit approximately equal. The eutter was then removed, and the soil from the infestation center transferred to a unit of the small isolation apparatus.

In describing the moisture content of the soils the term " moist" indieates a soil which had a slightly sensible wetness, while the term "saturated" denotes a soil which had been thoroughly soaked and its surface fairly covered with water.

It will be seen from an examination of Table 1, that the larvae did not manifest the migratory habit which has been attributed to them, since in no instance were they found as far as four inches from the center in which they were placed. In only 4 experiments (Table 1 . nos. $5,7,17$ and 19 ) were larvae recovered from the third zone, and in each of these cases less than 2 per cent. of the total number of larvae recovered had reached this zone. It is also apparent that neither the type of soil nor the presence of vegetation enter as factors in the extent of active migration of hookworm larvae, A thick grassy sod was not available at the time of these experiments, and in order to study the larvae under this environment the soil-clay loamwas first heavily sown with a mixture of oats and wheat. The larvae were not added to the infestation centers until the grass had formed a heavy root system, and had reached a height of 3 to 4 inches. No perceptible difference was observed in the extent of migration of the hookworm larvae, when exposed to direct sunlight under temperatures varying from $93^{\circ} \mathrm{F}$. to $101^{\circ} \mathrm{F}$.. (Experiment 20, Table 1). The migration pan was set out in direct sunlight during the day and returned to the laboratory at night. At no time was the soil allowed to become dry. As soon as a dry crust appeared on the surface it was evenly sprinkled with water, thus keeping it as uniformly "moist" as possible. While the sunlight had no apparent influence on the extent of spread of the Iarvae away from the infestation 
center, it had an indirect effect on the activities of the larvae within that area which is discussed in number eight of this series.

TABLE 1.

Experiments on the active migration of hookworm larvae. All these tests were made in the thirteen-inch pans.

\begin{tabular}{|c|c|c|c|c|c|c|c|c|}
\hline \multirow{2}{*}{ 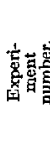 } & \multirow{2}{*}{ 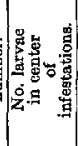 } & \multirow{2}{*}{ Type of soil. } & \multirow[b]{2}{*}{ Conditions. } & \multirow{2}{*}{$\begin{array}{c}\text { Time } \\
\text { larvae } \\
\text { remained } \\
\text { in } \\
\text { soil. }\end{array}$} & \multicolumn{4}{|c|}{$\begin{array}{l}\text { No. of H.W. larvae } \\
\text { recovered from }\end{array}$} \\
\hline & & & & & $\begin{array}{l}\dot{0} \\
\stackrel{0}{0} \\
\text { N }\end{array}$ & 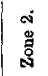 & $\begin{array}{l}0 \\
0 \\
0\end{array}$ & 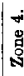 \\
\hline 1 & 800 & Clay loam & Moist, shade & 15 hours & 409 & 15 & 0 & 0 \\
\hline 2 & 1,000 & Clay " & " & $16 " 4$ & 583 & 274 & 0 & 0 \\
\hline 3 & 1,800 & Loose loam & $"$ & 40 & 1,395 & 128 & 0 & 0 \\
\hline 4 & 1,000 & Ioose “ & $a$ & $15 "$ & 460 & 406 & 0 & 0 \\
\hline 5 & 1,000 & Clay loam & $a$ & 7 days & 236 & 84 & 1 & 0 \\
\hline 6 & 1,000 & Clay " & $"$ & 7 : & 478 & 39 & 0 & 0 \\
\hline 7 & 512 & Clay " & $"$ & $11:$ & 89 & 145 & 3 & 0 \\
\hline 8 & 1,100 & Clay " & 4: & 21 & 13 & 5 & 0 & 0 \\
\hline 9 & 650 & Clay " & $"$ & $42 \quad 6$ & 1 & 0 & 0 & 0 \\
\hline 10 & 525 & Red clay loam & “ & 15 hours & 363 & 69 & 0 & 0 \\
\hline 11 & 500 & " " $"$ & " & 22 days & 6 & 3 & 0 & 0 \\
\hline 12 & 277 & Clay loam sod & " & 7 is & 60 & 10 & 0 & 0 \\
\hline 13 & 392 & " $"$ " & $"$ & 21 & 2 & 3 & 0 & 0 \\
\hline 14 & 361 & " $\quad$ " & “ & 30 & 1 & 1 & 0 & 0 \\
\hline 15 & 426 & "4. " " & " & 37 & 1 & 0 & 0 & 0 \\
\hline 16 & 498 & Sand & “ & 10 & 51 & 40 & 0 & 0 \\
\hline 17 & 451 & Sand & " & 22 & 77 & 16 & 1 & 0 \\
\hline 18 & 498 & Sand & $-"$ - & 29 & 51 & 40 & 0 & 0 \\
\hline 19 & 1,300 & Sand and clay & " $"$ & $8 "$ & 199 & 174 & $\mathbf{5}$ & 0 \\
\hline 20 & 500 & Clay loam & Moist, direet sun & 354 & 5 & 0 & 0 & 0 \\
\hline
\end{tabular}

Early in these experiments it was noted that there occurred a remarkable reduction from the original number of larvae placed in the infestation centers, even after a week's time. It will be noted, from Table 1, that this reduction increased with the number of days the larvae remained in the soil. Here, as well as in other experiments made, a large percentage of the larvae recovered had lost their sheaths.

This experimental evidence on the failure of the hookworm larvae to migrate in the soil is supported by similar findings of Cort and Payne (1922a, p. 137), in their study on the sources of hookworm infestation in a eane field. Instead of finding a uniform distribution 
of the larvae over the total area studied, they were found to be definitely localized at the places of soil pollution. Often where two soil samples were taken close together one would contain a large number of larvae, while the other would contain only a few or be even negative. As a specific example, approximately 1,000 hookworm larvae were isolated from a pint of soil taken from a pollution spot 15 yards into the cane. Pint samples taken from the areas within a radius of $1 \frac{1}{2}$ feet to 2 yards from this yielded from 0 to 53 hookworm larvae per sample. The environment here was seemingly in every way favorable for migration, yet during the entire time of the investigation, the larvae were always found at more or less definitely localized spots, at the places of soil pollution. That there oceurs little or no migration of the hookworm larvae even from centers of very heavy soil infestation has also been shown by Cort and Payne (1922b, p. 159) under conditions existing in a cacao grove. The evidence from these field studies and the data from the laboratory experiments given above show that it will be necessary to revise our present conception of the extent of the migrations of infective hookworm larvae, and make it seem very probable that it is only by mechanical means that hookworm larvae can spread from the place of their development.

WHEN PLACES OF SOIL INFESTATION BECOME DRY, DO HOOKWORM IJARYAE MIGRATE TO MORE FAVORABLE SITUATIONS?

To test this point, a large number of hookworm larvae were placed on a small spot in a 13-inch dripping pan, containing moist sand $1 \mathrm{~cm}$. in depth. A second area, to which no larvae were added, was located 8 inches away from the first. The whole surface was then evenly sprinkled with water. Water was afterwards added daily to the second area which alone was kept constantly moistened. Ten days later all the sand appeared to be thoroughly dry except that in and around the watered area. This was transferred to a unit of the small isolating apparatus, and upon examination, proved to be negative for hookworm larvae. A small amount of soil taken directly from the original infestation spot was placed on a glass slide, a few drops of water were added, and upon microseopial examination three shrivelled, completely disorganized hookworm larvae were found. The remaining soil of this area was then examined, but yielded no larvae. This experiment indicates that infective hookworm larvae cannot migrate from a drying area to a moist area nearby, but, of course, needs confirmation by a Jarger series of experiments. 


\section{ExPERIMENTS ON PASSIVE MigRation.}

In two experiments made in the same manner as those summarized in Table 1, except that water was added until the surface of the soils was covered, a fairly uniform distribution of the larvae was found in all zones. In the first, with clay loam soil, where 500 hookworm larvae were added to the infestation eenter, 72 larvae were recovered from that area, 70 from the second, 17 from the third and 3 from the fourth, eight days after the experiment was started. In the second, with a sand and clay soil, 1,300 larvae were placed in the center of infestation. Eight days later 83 larvae were recovered from Zone 1, 271 from Zone 2, 245 from Zone 3 and 258 from Zon'e 4.

As these two above experiments differed from those of Table 1 only in the amount of water added, it seemed that in these cases the larvae might have been mechanically carried out of the infestation centers by the surface water. In fact, in the examination of preparations in the counting of larvae, they were often found on the surface film.

To determine the numbers of larvae that might be carried from a given center by this means, the following experiments (see Table 2)

TABLE 2.

Showing number of hookworm larvae carried in surface film.

\begin{tabular}{|c|c|c|c|c|}
\hline $\begin{array}{l}\text { Exp. } \\
\text { No. }\end{array}$ & $\begin{array}{l}\text { No. larvae } \\
\text { used. }\end{array}$ & $\begin{array}{l}\text { Position of larvse } \\
\text { in soil. }\end{array}$ & $\begin{array}{l}\text { No. larvae } \\
\text { recovered. }\end{array}$ & $\begin{array}{l}\text { Per cent. } \\
\text { recovery. }\end{array}$ \\
\hline 1 & 222 & No larvae visible $\ldots \ldots \ldots \ldots \ldots \ldots$ & 52 & 23.4 \\
\hline 2 & 234 & No larvae visible $\ldots \ldots \ldots \ldots \ldots \ldots$ & 61 & 26.1 \\
\hline 3 & 100 & No larvae visible $\ldots \ldots \ldots \ldots \ldots \ldots$ & 28 & 28.0 \\
\hline 4 & 268 & Larvae protruding from surface....... & 117 & 43.6 \\
\hline 5 & 127 & Larvae protruding from surface...... & 38 & 29.9 \\
\hline 6 & 156 & Larvae protruding from surface...... & 57 & 36.5 \\
\hline
\end{tabular}

were made. Two hundred and twenty-two active hookworm larvae were placed in the center of a 6 -inch pudding pan, containing one inch of clay loam soil. The larvae remained undisturbed for several minutes when water was added, until the soil was well covered. The standing water was immediately drawn off with a pipette from all parts of the surface, except that in which the larvae had been placed. This was centrifugated and upon examination of the residue 52 hookworm larvae were found. This showed that 23.4 per cent. of the total number of larvae, placed in the infestation center, had been 
carried out by the water. Experiments 2 and 3 of this table were made under the same conditions as the first, and their results further illustrate the rôle water plays in the dissemination of hookworm larvae.

In the first three experiments of Table 2 no larvae were visible on the surface of the soil, at the time the water was added. In experiments 4,5 and 6 of the same table, the larvae had been placed in the soil 15 hours before the water was added. During that time they had established themselves on the surface of the soil, and were found protruding from the prominent soil particles within the infested area. Water was added as before, until the soil was well covered, and upon examination of the residue from the free water slightly higher percentages of the larvae were recovered than in the first three experiments (see Table 2). Apparently when the larvae are well established on the surface of the soil, they are more easily transferred to the surface film.

That hookworm larvae are carried away from centers of soil infestation by the washing of rains, under natural conditions, is indicated by the findings of Cort and Payne (1922, p. 141). Soil samples examined from the drains in the heavily infested area of the cane field studied, showed that the larvae were fairly evenly distributed for a distance of 50 yards. Soil pollution was found only in the higher parts of the drains and their environs. The authors corfsider that this distribution in the drains is due to the larvae being washed down from the upper ends of the drains, as well as from the areas drained.

To determine the number of hookworm larvae carried on the feet of man, after passage through areas of heavy soil infestation, the soil was scraped from the shoes of three persons, after they had completed a pollution survey in a cane field (see Cort and Payne, 1922a, p. 115). Soil obtained in this way was examined for hookworm larvae by the routine method, on six different oecasions. The findings varied from 2 to 344 hookworm larvae per person. No appreciable difference was noted in the number of larvae obtained, whether rain had fallen twenty-four hours previous to the survey or not. This is explained by the fact that although the amount of rainfall varied, the soil in the cane was always moist enough to cling to the shoes in considerable amounts. The finding of 344 hookworm larvae in the soil adhering to the shoes of one person is significant. This person bad undoubtedly stepped in a "nest" of larvae which was immediately transferred to his shoe. Had he been barefoot and the mud remained on the skin, 
the resulting infestation would probably have been heavy from this one exposure. Again, had the soil been washed off or dropped on a frequented path, there would have been danger to others.

Domestic animals passing through infested areas likewise enter as factors in the dissemination of hookworm larvae. No actual experiments were made to determine this point, but, from observations made, both in cacao groves and cane fields, it seemed evident that a considerable amount of infested soil may be scattered about in this fashion.

The results of my experiments, as well as field observations, have shown that the hookworm larvae are not mignatory during their free life in the soil of Trinidad, but that they can be spread to some extent mechanically. Further investigations are needed to test out, under a variety of conditions, the points brought out in this study.

\section{SUMmaRT.}

1. Experiments carried on in Trinidad, British West Indies, from May to September, 1922, showed that infective hookworm larvae placed on moist soils do not migrate in periods from 15 hours to 42 days.

2. Experiments show that hookworm larvae may be carried out from centers of soil infestation by surface water, and that they can establish themselves in the new locations when the water recedes.

3. Hookworm larvae were not found to migrate to favorable situations when their original environments become unfavorable.

4. Soil scraped from the shoes of mien passing through infested areas was found to contain hookworm larvae. It is possible that paths leading to such areas, as well as the immediate surroundings of dwellings, become centers of infestation by the dropping of such soil.

5. During the time the larvae remained in the soil there occurred a reduction in their numbers, which inereased with the number of days the experiment lasted.

Batrimann, G.

\section{LITERATURE CITED.}

1917. Über Ankylostomiasis, deren Ausbreitungsbedingungen dureh die Bodeninfection und deren Bekämpfung. Geneesk. Tijdsehr. Ghandlek, A. C. Nederl. Indie, Batavia, LVII, 579-669.

1918. Animal parasites and human disease, N. Y., 570 . 
Cort, W. W., Aqkert, J. E., Augustine, D. L., and Patne, F. K.

1922. Investigations on the eontrol of hookworm disease. II. The description of an apparatus for isolating hookworm larvae from soil. AMER. JoUr. HYG., II, 1-16.

Cont, W. W., and Payne, G. G.

1922a. Investigations on the control of hookworm disease. VI. A study on the effect of hookworm control measures on soil pollution and infestaition in a sugar estate. AMFr. JoUR. HrG., MI, $107-148$.

1922b. Investigations on the control of hookworm disease. VII. An epidemiologic study of hookworm disease in a cacao estate. AMER. Jour. HYG., II, 149-161.

NicoLl, WM.

1917. Observations on the infuence of salt and other agents in modifying the larval development of the hookworms, Ankylostoma duodenale and Necator americanus. Parasitology, Cambridge

Ozgard, A. T. (Eng.), IX, 157-189.

1909. Life-history of Ankylostoma duodenale. Brit. M. J., London, II, 779-780. Porto Rieo Anemia Commission.

1904. Repart of the Commission for the Study and Treatment of "Anemia " in Porto Rico, Bur. Print and Supplies. San Juan, n. d., 335.

PrICE, N. J.

1910. Climatie, soil and general conditions in Maryland with reference to SMITH, C. A. hookworm disease. Maryland M. J., Balt., LIII, 201-206.

1902. Uneinariasis in the South. J. Amer. Med. Ass., Chie, XLI, 709713 .

Williams, C, B.

1921. Report on the froghopper-blight of sugar cane in Trinidad. Gov. Print. No. 1, 170 . 